\title{
Exosomes released by granulocytic myeloid-derived suppressor cells attenuate DSS-induced colitis in mice
}

\author{
Yungang Wang ${ }^{1,2, *}$, Jie Tiann ${ }^{2, *}$, Xinyi Tang ${ }^{1, *}$, Ke Rui ${ }^{2}$, Xinyu Tian ${ }^{2}$, Jie Ma², Bin Ma ${ }^{2}$, \\ Huaxi $\mathbf{X u}^{2}$, Liwei $\mathrm{Lu}^{3}$, Shengjun Wang ${ }^{1,2}$ \\ ${ }^{1}$ Department of Laboratory Medicine, The Affiliated People's Hospital, Jiangsu University, Zhenjiang, China \\ ${ }^{2}$ Institute of Laboratory Medicine, Jiangsu Key Laboratory of Laboratory Medicine, Jiangsu University, Zhenjiang, China \\ ${ }^{3}$ Department of Pathology, The University of Hong Kong, Hong Kong, China \\ "These authors contributed equally to this work
}

Correspondence to: Shengjun Wang, e-mail: sjwjs@ ujs.edu.cn

Keywords: inflammatory bowel disease, exosomes, myeloid-derived suppressor cells, inflammation, Immunology and Microbiology Section, Immune response, Immunity

Received: November 09, 2015

Accepted: January 29, 2016

Published: February 11, 2016

\section{ABSTRACT}

Myeloid-derived suppressor cells (MDSC) have been described in inflammatory bowel disease (IBD), but their role in the disease remains controversial. We sought to define the effect of granulocytic MDSC-derived exosomes (G-MDSC exo) in dextran sulphate sodium (DSS)-induced murine colitis. G-MDSC exo-treated mice showed greater resistance to colitis, as reflected by lower disease activity index, decreased inflammatory cell infiltration damage. There was a decrease in the proportion of Th1 cells and an increase in the proportion of regulatory $T$ cells (Tregs) in mesenteric lymph nodes (MLNs) from G-MDSC exo-treated colitis mice. Moreover, lower serum levels of interferon (IFN)- $Y$ and tumor necrosis factor (TNF)- $a$ were detected in G-MDSC exotreated colitis mice. Interestingly, inhibition of arginase (Arg)-1 activity in G-MDSC exo partially abrogated the spontaneous improvement of colitis. In addition, G-MDSC exo could suppress $\mathrm{CD4}^{+} \mathrm{T}$ cell proliferation and $\mathrm{IFN}-\mathrm{Y}$ secretion in vitro and inhibit the delayed-type hypersensitivity (DTH) response, and these abilities were associated with Arg-1 activity. Moreover, G-MDSC exo promoted the expansion of Tregs in vitro. Taken together, these results suggest that G-MDSC exo attenuate DSS-induced colitis through inhibiting Th1 cells proliferation and promoting Tregs expansion.

\section{INTRODUCTION}

Inflammatory bowel disease (IBD) is a non-specific, inflammatory, autoimmune disorder with abdominal pain, diarrhea, and bloody stools that may lead to the development of cancer [1]. In humans, IBD includes ulcerative colitis (UC) and Crohn's disease (CD) and is caused by the body's immune response to the normal flora which should normally be tolerable and other factors of host [2]. Studies have shown that Th1 cells and secreted inflammatory factors promoted the development of IBD [3]. Hofseth and colleagues showed that resveratrol protected against DSS induced colitis mouse through upregulating the silent mating type information regulation-1 (SIRT-1) of immune cells in the colon [4]. However, regulatory $\mathrm{T}$ cells (Tregs) play positive roles in maintaining intestinal immune balance [5]. Tregs are decreased in patients with IBD [6], resulting in an imbalance between pro-inflammatory Th1 cells and anti-inflammatory Tregs. The incidence of IBD is on the rise globally. Currently, IBD patients are treated symptomatically [7], and there is an urgent need for effective and curative medical treatments. MDSC are broadly considered as a heterogeneous population of immature myeloid cells that dampen the immune response and accumulate in pathological cases of tumor, inflammation and pathogen infection [8]. MDSC in mice are widely identified as Gr-1 (consisting of Ly6G and Ly6C markers) and CD11b double-positive cells. The two major populations of MDSC can be differentiated by morphologic characteristics and the expression of Gr-1 molecule; CD11b ${ }^{+}$Ly $6 \mathrm{G}^{+} \mathrm{Ly} 6 \mathrm{C}^{\text {low }}$ cells with granulocyte-like morphology are defined as granulocytic MDSC (G-MDSC), and $\mathrm{CD} 11 \mathrm{~b}^{+}$Ly6G $\mathrm{G}^{-}$Ly6C $\mathrm{C}^{\text {high }}$ cells with monocyte-like morphology are defined as monocytic MDSC (M-MDSC) 
[9]. Both types expand greatly in different tumor models, and the number of G-MDSC is significantly higher than that of M-MDSC. Moreover, the immunosuppressive mechanism of G-MDSC is different from that of M-MDSC [10]. G-MDSC suppress innate and adaptive immune responses through mechanisms involving L-arginine metabolism and reactive oxygen species (ROS) production [11, 12]. These immunosuppressive roles of G-MDSC imply that they can be used to treat autoimmune diseases [13]. In fact, MDSC have been employed to treat collagen-induced arthritis (CIA) and showed a certain effect on reducing severity [14]. Ioannou and colleagues demonstrated that G-MDSC ameliorated experimental autoimmune encephalomyelitis through inhibition of encephalitogenic Th1 and Th17 immune responses [15]. Another study showed that the increased elimination of G-MDSC was due to the extracellular trap (ET) formation driven by the inflammatory milieu of lupus and demonstrate the role of cytokines such as IFN- $\alpha$, IFN- $\gamma$ and IL- 6 in the induction of ET released by G-MDSC correlated with the production of ROS [16]. However, the exact role of MDSC in IBD pathogenesis is unclear, and there are controversies regarding their immunosuppressive functions in this context $[17,18]$.

Exosomes (exo) are 30-150-nm phospholipid bilayerenclosed vesicles that are either released from the parental cell into the extracellular space when multivesicular bodies fuse with the plasma membrane or released directly from the plasma membrane [19]. One study demonstrated that almost all living cells can secrete exo, which are widely present in various biological fluids [20]. It is becoming increasingly clear that exo have specialized functions and play key roles in intercellular signaling, coagulation, and waste management [21]. Exo are also reportedly involved in immune response, apoptosis, angiogenesis, inflammation, and tumor development [22]. Consequently, there is growing interest in their clinical applications for therapy, prognosis, and disease and health biomarkers. From the perspective of disease prevention, exo exhibit more advantages than parental cells [23]. Firstly, exo storage and transport are simple, and they can be used with less cytotoxicity and biohazard. Secondly, the complex molecules on the surface of exo offer potential mechanisms of homing to specific tissues and microenvironments. Lastly, the therapeutic proteins and nucleic acids carried by exo are not easily degraded. Studies have demonstrated that immature dendritic cell-derived exo are a promising subcellular vaccine for autoimmunity, and exo released from iDCs secreting transforming growth factor (TGF)- $\beta 1$ prevented the development of autoimmune diseases [24].

In this study, G-MDSC were sorted from the spleens of tumor-bearing mice, then G-MDSC exo were isolated from the culture supernatant of G-MDSC by serial centrifugation and purification with an isolation kit. We found that G-MDSC exo could attenuate DSS-induced colitis and restore intestinal immune balance. Subsequently, we confirmed that G-MDSC exo suppress $\mathrm{CD}^{+} \mathrm{T}$ cell proliferation and the delayed-type hypersensitivity (DTH) response, and these roles were partially related to arginase (Arg)-1 activity. Moreover, G-MDSC exo could promote Tregs expansion in vitro. Collectively, these data indicate that G-MDSC exo have a strong ability to reduce the severity of DSS-induced colitis. Our findings provide a potential immunotherapy for IBD and other autoimmune diseases.

\section{RESULTS}

\section{Extraction and identification of G-MDSC exo}

G-MDSC were isolated from the spleen of tumorbearing mice and analyzed by FCM; cell purity was $>95 \%$ (Figure 1A). We could acquire $1 \times 10^{7} \mathrm{G}-\mathrm{MDSC}$ from one tumor-bearing mouse. G-MDSC were cultured in vitro, and culture supernatants were collected after $20 \mathrm{~h}$. Exosomes in the supernatants were purified by the method of differential centrifugation followed by use of exosomes extraction kits. G-MDSC exo were observed by transmission electron microscopy, which revealed that most of the exosomes displayed closed round vesicles with diameters of 30-150 nm (Figure 1B and 1C). Further characterization indicated that G-MDSC exo had a similar level of exoassociated CD63 (Figure 1D). In contrast, calnexin was not detected in the purified G-MDSC exo preparations (Figure 1D), indicating that G-MDSC exo were free from contamination with non-exo membrane proteins. We could acquire 3-5 $\mu \mathrm{g}$ G-MDSC exo from $1 \times 10^{6} \mathrm{G}-\mathrm{MDSC}$.

Arg-1 is one of the most important molecules that plays a critical role in the immunosuppressive function of G-MDSC. To determine whether G-MDSC exo contain Arg-1 activity, the Arg-1 activity of G-MDSC exo was detected with an assay kit according to the manufacturer's instructions. The results showed Arg-1 activity in G-MDSC exo (Figure 1E). Additionally, the specific arginase inhibitor $\mathrm{N}^{\omega}$-hydroxy-nor-Arginine (nor-NOHA, also $\mathrm{NN}$ ) was added to the G-MDSC culture system, and this type of exo was isolated and termed (G-MDSC+NN) exo; they showed significant decrease of Arg-1 activity (Figure 1E).

\section{G-MDSC exo attenuate DSS-induced experimental colitis in mice}

To test whether G-MDSC exo can ameliorate colitis, C57BL/6 mice were injected i.p with G-MDSC exo (30 $\mu \mathrm{g} /$ mouse/injection) on days 2 , 4 , and 6 after colitis induction. Multiple observations collectively indicated that G-MDSC exo-treated mice were considerably less susceptible to DSS-induced colitis compared to other groups. Firstly, the DAI of G-MDSC exo-treated colitis mice was lower than in colitis mice or (G-MDSC+NN) exo-treated colitis mice on day 4 after the initiation of DSS treatment. Moreover, this difference gradually increased over time (Figure 2A). 
Secondly, DSS treatment caused severe bloody stools that persisted until the sacrifice of colitis mice or $(\mathrm{G}-\mathrm{MDSC}+\mathrm{NN})$ exo-treated colitis mice. This change was not observed in G-MDSC exo-treated colitis mice (Figure 2B). Thirdly, we measured the length of colon from mice in different groups. Results showed that the length of colon in colitis mice or $(\mathrm{G}-\mathrm{MDSC}+\mathrm{NN})$ exo-treated colitis mice is shorter than G-MDSC exo-treated colitis mice (Figure 2C). Finally, histologic examination of colonic sections revealed complete disruption of the colonic architecture in colitis mice, whereas G-MDSC exo-treated colitis mice retained intact colonic architecture, and the severity of disease in (G-MDSC+NN) exo-treated colitis mice was greater than G-MDSC exotreated colitis mice (Figure 2D). Consistent with histologic observations, the histologic scoring of G-MDSC exotreated colitis mice was significantly lower than colitis mice, G-MDSC exo-treated colitis mice or (G-MDSC+NN) exotreated colitis mice (Figure 2E). Taken together, these results strongly support the hypothesis that G-MDSC exo could attenuate DSS-induced murine experimental colitis and suggest that Arg-1 plays an important role in this process.

\section{G-MDSC exo prevent Th1 cell development and promote Tregs expansion in murine experimental colitis}

Th1 cells and IFN- $\gamma$ are crucial for the pathogenesis of IBD, and TNF- $\alpha$ also participates in IBD pathogenesis [25]. However, Tregs could maintain the intestinal immune balance and play a protective role in IBD [5]. To understand the mechanisms underlying the action of G-MDSC exo against colitis, the percentages of Tregs and Th1 cells in MLNs were analyzed by FCM, and the serum levels of IFN- $\gamma$ and TNF- $\alpha$ were determined by ELISA. As shown in Figure 3A, following treatment with G-MDSC exo, the percentage of Th1 cells was significantly lower than that in colitis, Neu exo-, or (G-MDSC+NN) exo-treated colitis mice. However, the percentage of Tregs in G-MDSC exo-treated colitis mice was significantly higher than that in colitis or Neu exo-treated colitis mice (Figure 3B). Moreover, markedly lower levels of IFN- $\gamma$ and TNF- $\alpha$ were detected in the serum of G-MDSC exo-treated colitis mice compared with that in other groups of colitis mice
A

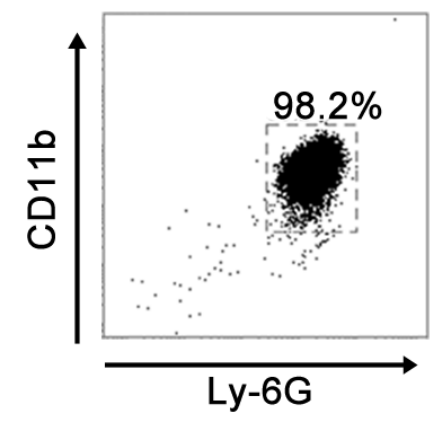

B

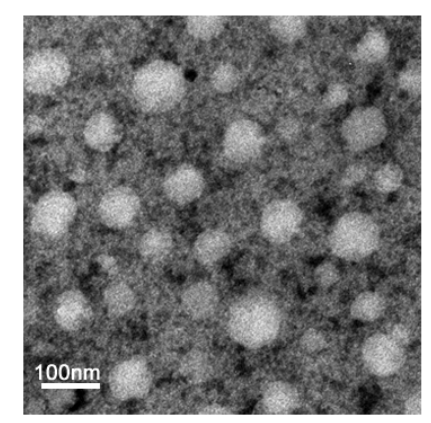

C

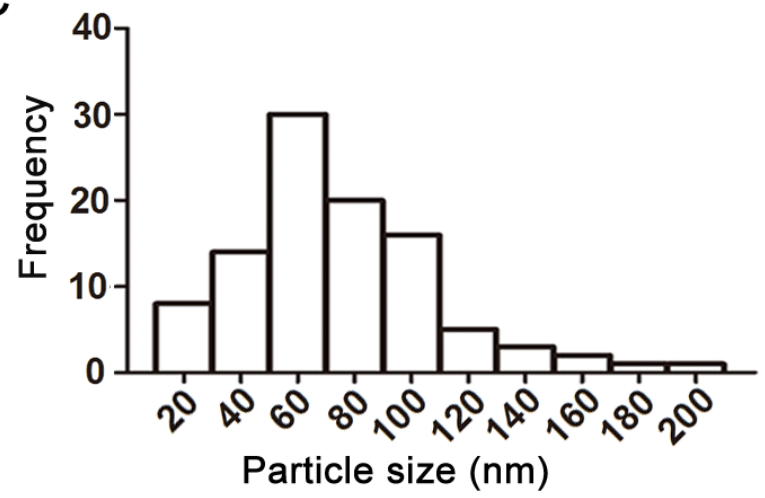

D

E

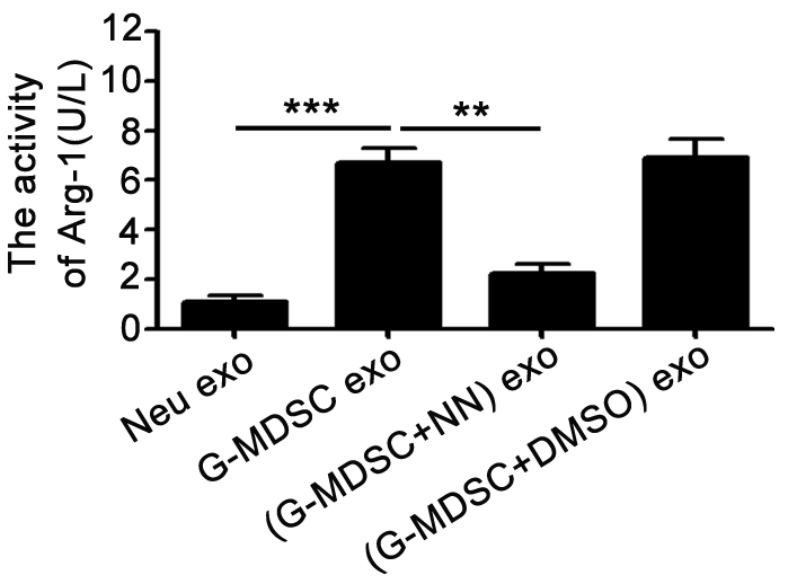

Figure 1: Extraction and identification of G-MDSC exo. (A) Immunomagnetic beads were used to sort G-MDSC from the spleens of tumor-bearing mice. Ly-6G and CD11b expression levels were analyzed by FCM. (B) Representative transmission electron micrograph of G-MDSC exo (magnification, $\times$ 80,000; scale bar $=100 \mathrm{~nm}$ ). $(\mathbf{C})$ The particle-size distribution of G-MDSC exo dispersed in fluid. (D)CD63 and calnexin expressions were detected by western blot. Data shown in A, B, and D are from one of three independent experiments. (E)Exosome Arg-1 activity was detected with an Arg-1 activity assay kit. In the inhibition assay, G-MDSC were treated with the inhibitor nor-NOHA. Data are shown as the mean \pm SEM of each group $(n=6)$ pooled from three independent experiments. ${ }^{*} p<0.01, * * * p<0.001$, analyzed by ANOVA and $Q$ test. 
A

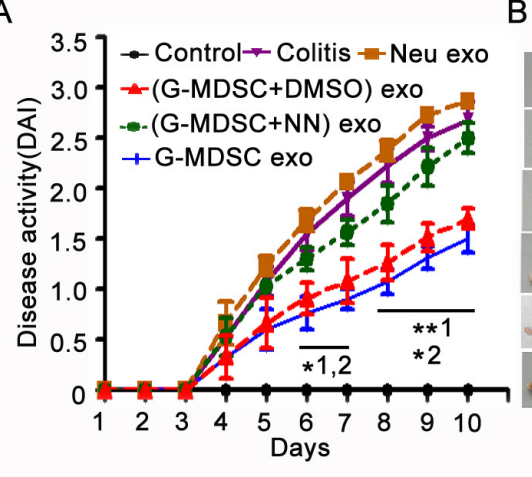

D

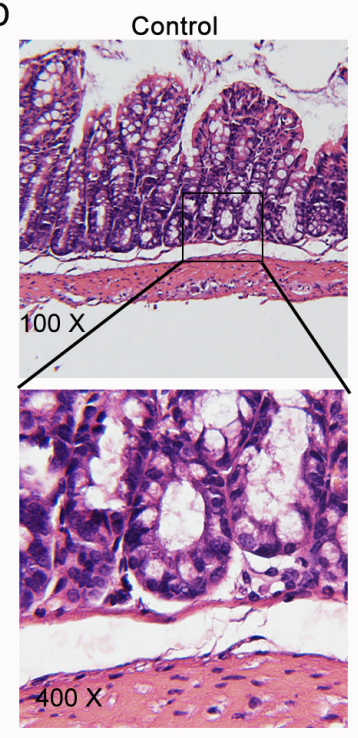

$(\mathrm{G}-\mathrm{MDSC}+\mathrm{NN})$ exo

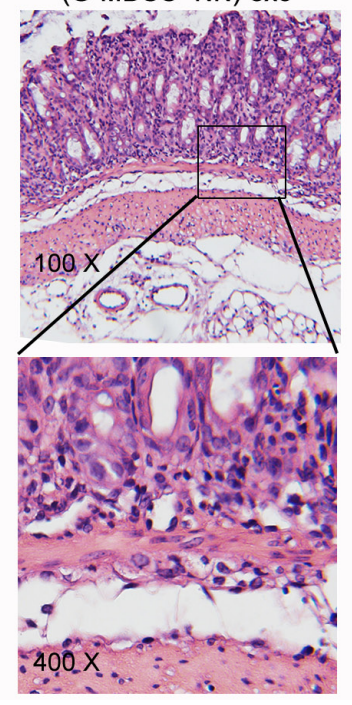

B
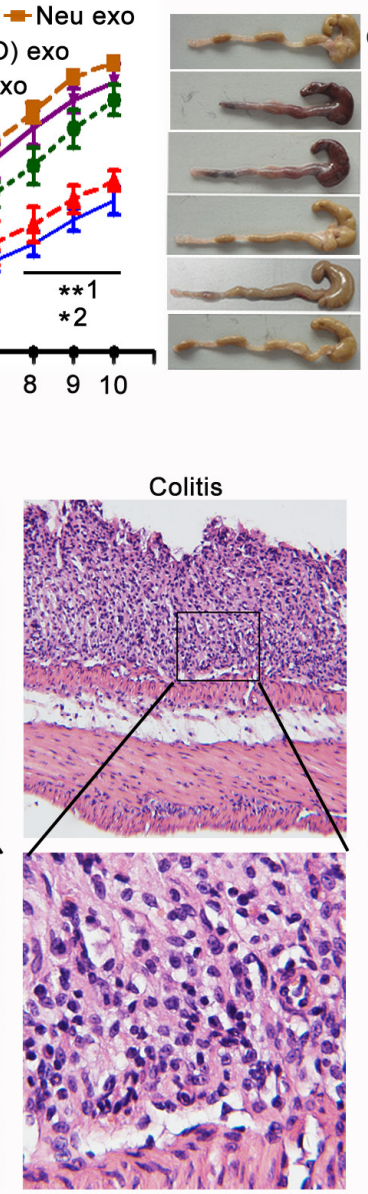

(G-MDSC+DMSO) exo

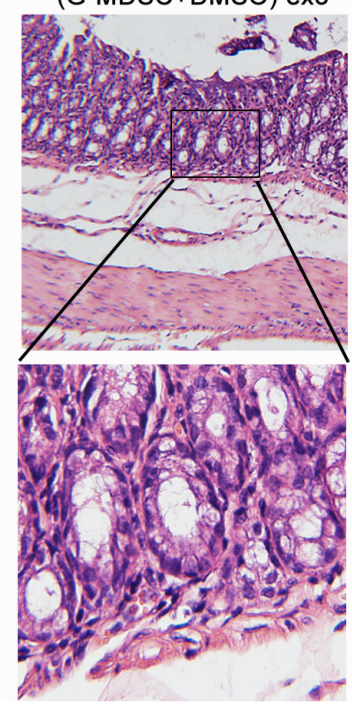

C
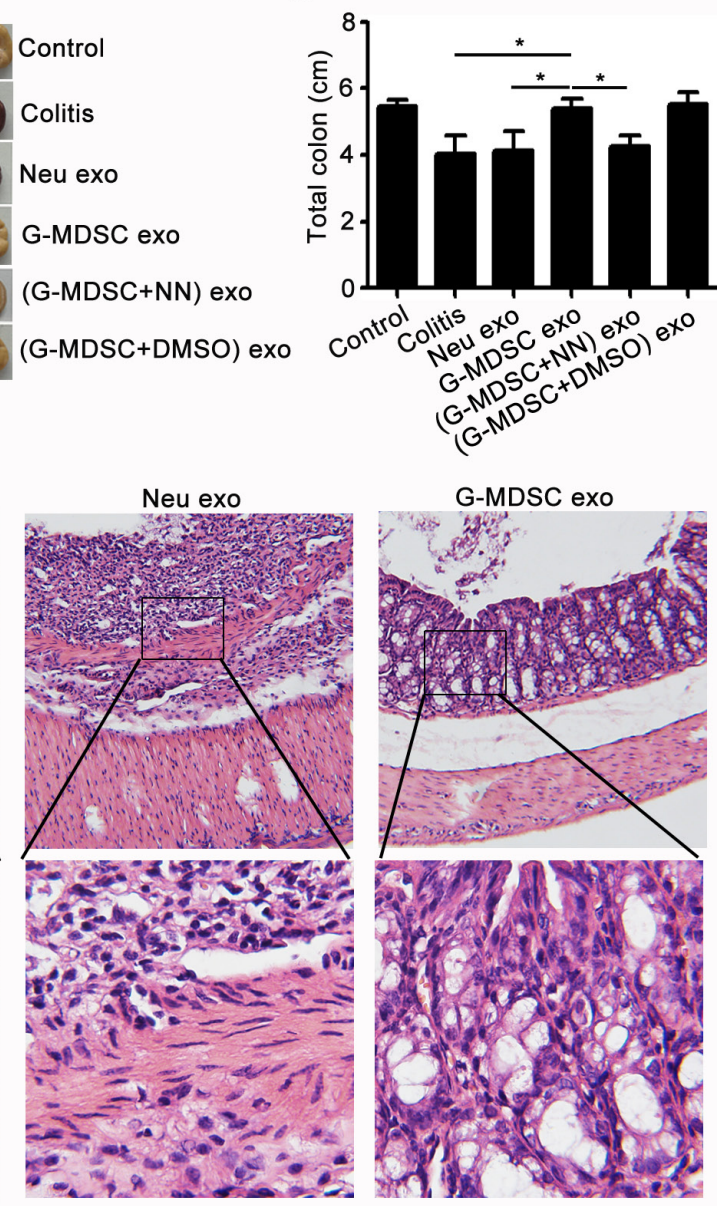

$\mathrm{E}$

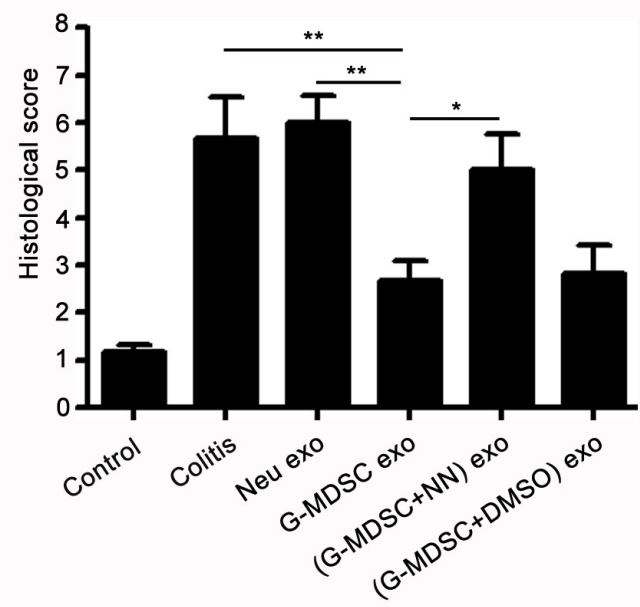

Figure 2: G-MDSC exo attenuate the severity of DSS-induced colitis. Murine experimental colitis was induced in C57BL/6 mice ( $n=10$ /group) by providing $2.5 \%$ DSS solution in their drinking water for 10 days. Mice received i.p. injections with exosomes (30 $\mathrm{\mu g} /$ mouse/injection) on days 2, 4, and 6. (A) Disease activity was determined daily as described in the methods. Mice were sacrificed on day 8 by eye bloodletting followed by cervical dislocation. Colon sections obtained from mice were analyzed for their outward appearance (B), length (C), degree of inflammation (D) and H \& E histologic scoring. (E) All data are presented as the mean \pm SEM from one of three independent experiments. ${ }^{*} p<0.05,{ }^{*} p<0.01 ; 1$, G-MDSC exo-treated colitis mice versus colitis mice; 2, G-MDSC exo-treated colitis mice versus (G-MDSC+NN) exo-treated colitis mice, analysis with ANOVA and $Q$ test. The mice of the control group had no DSS treatment. The mice of the colitis group had DSS treatment, while no exo treatment. All other experimental groups had DSS and different exos treatment. 
A
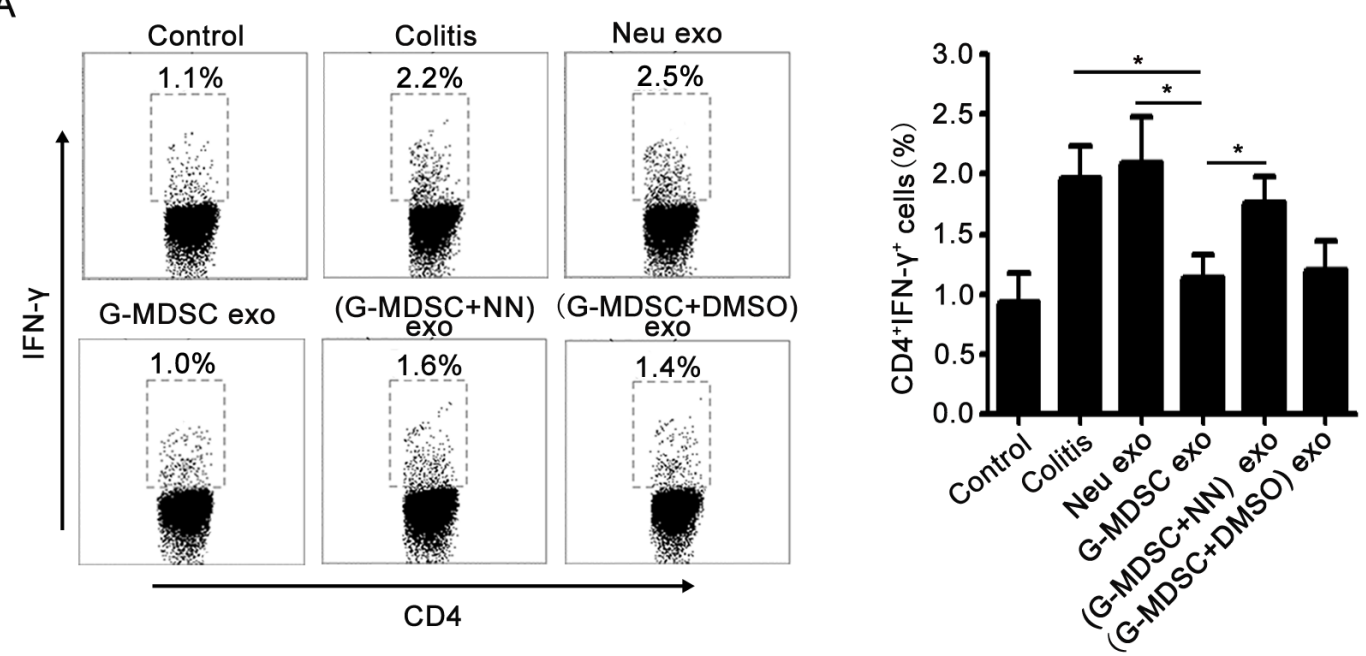

B
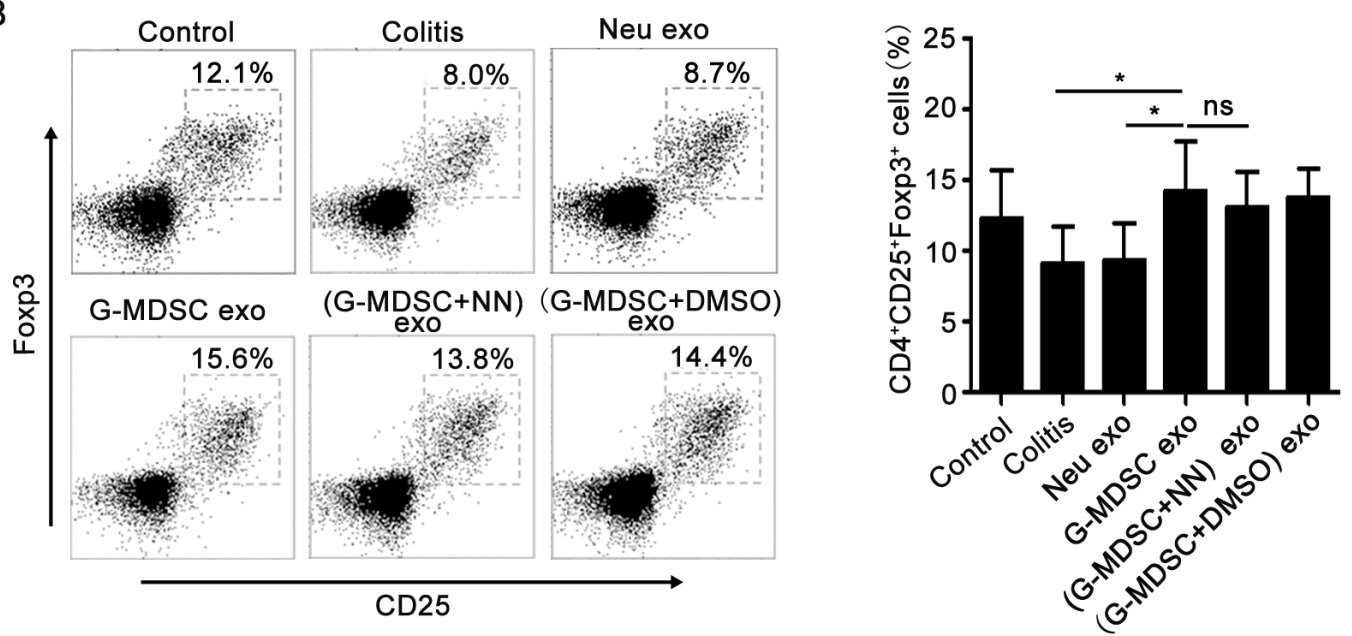

C
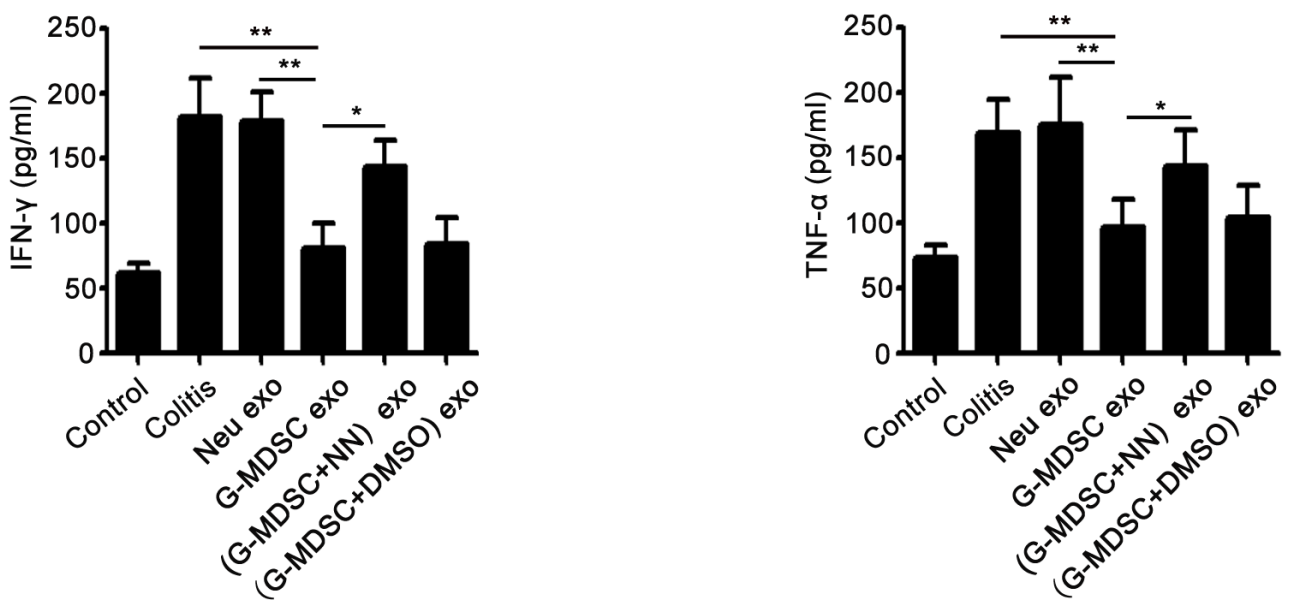

Figure 3: G-MDSC exo prevent the Th1 cell response and expand Tregs in murine experimental colitis. Mice were sacrificed, and lymphocytes from the MLNs of different groups of DSS-induced colitis mice were isolated on day 8. (A) For Th1 cell detection, lymphocytes were stimulated for $5 \mathrm{~h}$ with $1 \mu \mathrm{g} / \mathrm{ml}$ ionomycin and $50 \mathrm{ng} / \mathrm{ml}$ phorbol myristate acetate in the presence of $2 \mathrm{mg} / \mathrm{ml}$ monensin at $37^{\circ} \mathrm{C}$ and stained with anti-mouse CD4 and IFN- $\gamma$ mAbs according to the manufacturer's protocols. The percentage of Th1 cells was analyzed by FCM (left), and the statistical analysis results are shown (right). (B) For the detection of Tregs, lymphocytes were stained with anti-mouse CD4, CD25, and Foxp3 mAbs as described in the methods. The percentage of Tregs was analyzed by FCM (left), and the statistical analysis results are shown (right). (C) Serum cytokine concentrations in different groups after 8 days of DSS treatment. Data are shown as the mean \pm SEM of each group $(n=10)$ pooled from three independent experiments. ${ }^{*} p<0.05,{ }^{* *} p<0.01$, ns: not significant, analyzed by ANOVA and $Q$ test. 
(Figure 3C). Hence, our data indicate that treatment with G-MDSC exo inhibits Th1 cell responses but enhances Tregs, which contributes to the inhibition of colitis.

\section{G-MDSC exo suppress CD4 ${ }^{+} \mathrm{T}$ cell proliferation and IFN- $\gamma$ secretion in vitro}

Based on the immunosuppressive effect of G-MDSC exo on Th1 cells in DSS-induced murine colitis, we examined the role of G-MDSC exo in $\mathrm{CD}^{+} \mathrm{T}$ cell proliferation and IFN- $\gamma$ secretion from $\mathrm{CD}^{+} \mathrm{T}$ cells in vitro. Moreover, we observed the role of Arg-1 activity in the immunosuppression of G-MDSC exo. In the presence of anti-CD3 and anti-CD28 mAbs, $\mathrm{CD}^{+} \mathrm{T}$ cells isolated from the spleen of male wild-type C57BL/6 mice were cultivated in the presence of varying concentrations of G-MDSC exo or equimolar concentrations of $\mathrm{Neu}$ exo for 3 days. The CPM values in G-MDSC exo-treated groups were lower than in the untreated or Neu exo-treated groups, and the degree of CPM value reduction in G-MDSC exotreated groups correlated with the amount of G-MDSC exo (Figure 4A). However, the CPM values in medium and high concentrations (G-MDSC $+\mathrm{NN}$ ) exo-treated groups were significantly lower than those of G-MDSC exo-treated groups (Figure 4B). Notably, the changes of
IFN- $\gamma$ levels in culture supernatants were consistent with the changes of $\mathrm{CD} 4^{+} \mathrm{T}$ cell proliferation in different groups (Figure 4C and 4D). These results confirmed that G-MDSC exo suppressed $\mathrm{CD}^{+} \mathrm{T}$ cell proliferation and IFN- $\gamma$ secretion in a dose-dependent manner, and this inhibitory effect correlated with Arg-1 activity.

\section{G-MDSC exo suppress DTH response}

The DTH reaction mainly correlated with Th1 cells. To further confirm the role of G-MDSC exo in suppressing the response of $\mathrm{CD}^{+} \mathrm{T}$ cells in vivo, we investigated the role of G-MDSC exo in DTH. The DTH model involved an OVA challenge in mouse footpads, and footpad swelling was measured at a given time after the challenge. The DTH response was significantly suppressed in mice treated with G-MDSC exo before the OVA challenge (Figure 5). Moreover, this effect was weakened in $(\mathrm{G}-\mathrm{MDSC}+\mathrm{NN})$ exo-treated mice (Figure 5).

\section{G-MDSC exo promote TGF- $\beta$-induced Tregs generation from $\mathrm{CD4}^{+} \mathrm{T}$ cells in vitro}

Given the effect of G-MDSC exo on Tregs expansion in murine IBD and previous reports indicated that MDSC
A

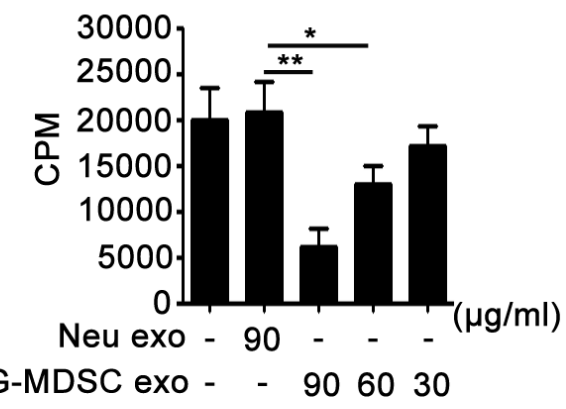

C

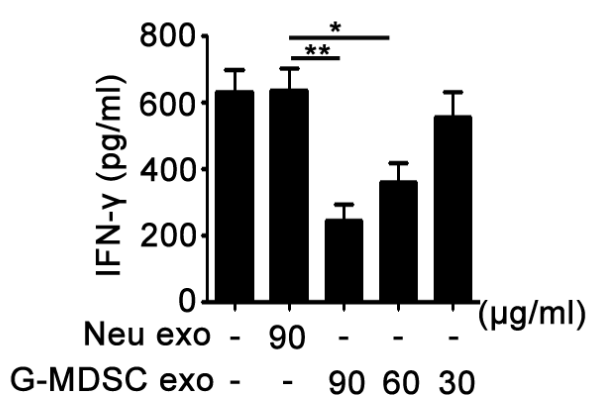

B

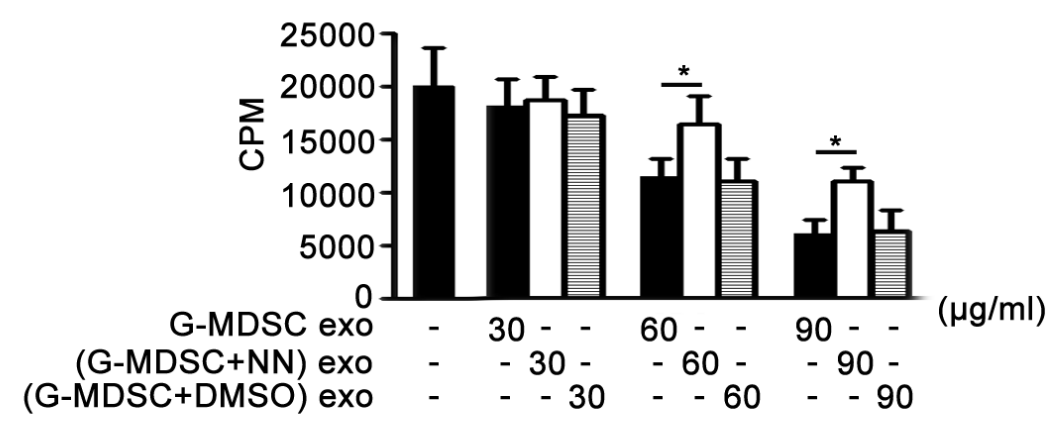

D

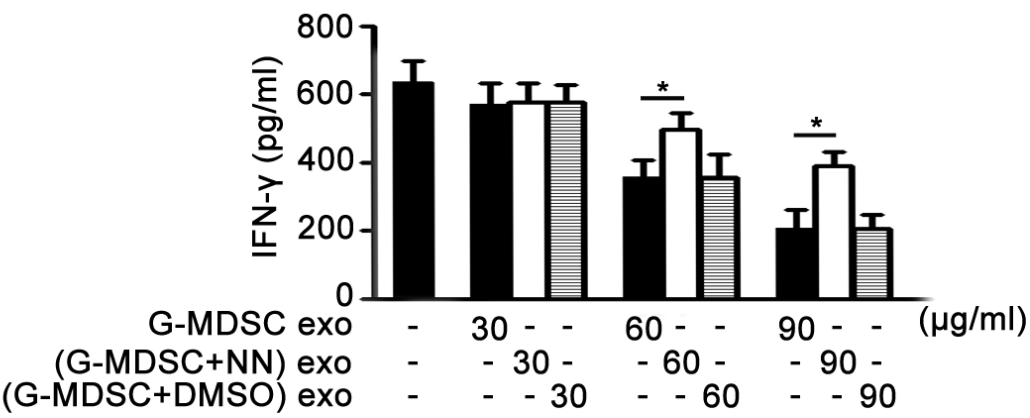

Figure 4: G-MDSC exo suppress $\mathrm{CD4}^{+} \mathrm{T}$ cell proliferation and IFN- $\gamma$ secretion correlating with Arg-1 activity in vitro. (A and B). G-MDSC exo suppress $\mathrm{CD}^{+} \mathrm{T}$ cell proliferation through Arg-1 activity. $\mathrm{CD} 4^{+} \mathrm{T}$ cells were treated with G-MDSC exo (A) or/ and (G-MDSC $+\mathrm{NN}$ ) exo (B) at different concentrations for $72 \mathrm{~h}$. The cultivation system was stimulated with anti-CD3 $\mathrm{mAb}(2 \mu \mathrm{g} / \mathrm{ml})$ and anti-CD28 mAb $(2 \mu \mathrm{g} / \mathrm{ml})$. Cell proliferation was measured by $\left[{ }^{3} \mathrm{H}\right]$-thymidine incorporation. (C and $\left.\mathbf{D}\right)$. G-MDSC exo suppress IFN- $\gamma$ secretion through Arg- 1 activity. The levels of IFN- $\gamma$ in culture supernatants from the $\mathrm{CD}^{+} \mathrm{T}$ cell proliferation system were detected using sandwich ELISAs. Data are shown as the mean \pm SEM of each group $(n=6)$ pooled from three independent experiments. ${ }^{*} p<0.05$, ** $p<0.01$, analyzed by ANOVA and $Q$ test. 
promoted Tregs expansion [26, 27]. We assumed that G-MDSC exo might promote the generation of Tregs from $\mathrm{CD}^{+} \mathrm{T}$ cells. To test this hypothesis, we evaluated the influence of G-MDSC exo on the expansion of Tregs from $\mathrm{CD}^{+} \mathrm{T}$ cells. $\mathrm{CD} 4^{+} \mathrm{T}$ cells isolated from C57BL/6 mice splenocytes were cultured for $72 \mathrm{~h}$ in the presence or absence of exo isolated from G-MDSC or neutrophils. Tregs percentages were determined by FCM. As shown in Figure 6A and 6B, a significant dose-dependent increase in Tregs percentage was observed in the presence of G-MDSC exo.

\section{DISCUSSION}

Exosomes are highly abundant in biologic fluids where they transfer information between cells. A report showed that MDSC isolated from BALB/c mice carrying 4T1 mammary carcinomas shed exosomes that contain multiple bioactive components derived from many subcellular compartments and are associated with diverse functions [22]. In this study, we found G-MDSC exo were bilayered vesicles as having diameters in the 30-150-nm range by transmission electron micrographs, which is consistent with previously described exosomes [28]. It is noteworthy that G-MDSC exo possess Arg-1 activity, which plays a critical role in the immunosuppressive function of G-MDSC. Overall, these results indicate that G-MDSC exo share some biological functions with their parental cells.

Although studies have attempted to utilize MDSC to suppress the autoimmune response and limit tissue injury in the context of EAE $[15,29]$ and CIA $[14,30]$, and get beneficial results. However, the roles of MDSC in IBD pathogenesis remain unclear, and the reports of immunosuppressive functions of MDSC in IBD are fairly controversial [17, 18]. Haile et al showed that MDSC frequency dramatically increased during intestinal inflammation in a $\mathrm{CD}^{+}$T-cell-mediated mouse model of IBD and suppressed IFN- $\gamma$ secretion from T cells, and transferred MDSC decreased intestinal inflammation [31]. Recruited myeloid cells may acquire antigen-presenting functions after undergoing a series of phenotypic and functional changes and stimulate cytokine production by effector Th1/Th17 cells in chronic colitis [32]. Moreover, inflammatory monocytes recruited in the lamina propria of colon may differentiate into proinflammatory dendritic cells [33]. However, these cells express inducible nitric oxide synthase and Arg-1, suggesting a more activated state resulting in an inability to suppress activated/ effector Th1/Th17 cells [34]. Considering the exact role of MDSC in IBD pathogenesis is unclear, and the clear immunosuppression and rich content of G-MDSC in tumor-bearing mice, we used G-MDSC exo to inhibit the development of DSS-induced colitis. The application of G-MDSC exo attenuated DSS-induced colitis, which was accompanied by a decrease in the number of Th1 cells and an increase in the number of Tregs from MLNs. Moreover, G-MDSC exo reduced the serum levels of IFN- $\gamma$ and TNF- $\alpha$ in DSS-induced colitis mice. Inhibition of Arg-1 activity with nor-NOHA partly attenuated the improvement of DSS-induced colitis by G-MDSC exo. G-MDSC play the role of immune suppression by the production of ROS, Arg-1 and generation of NO [10]. Peroxynitrite which formed by the cooperative activity of ROS with $\mathrm{NO}$ is another factor that inhibits effector T cells [35]. Peroxynitrite leads to the nitration of tyrosines in the T-cell

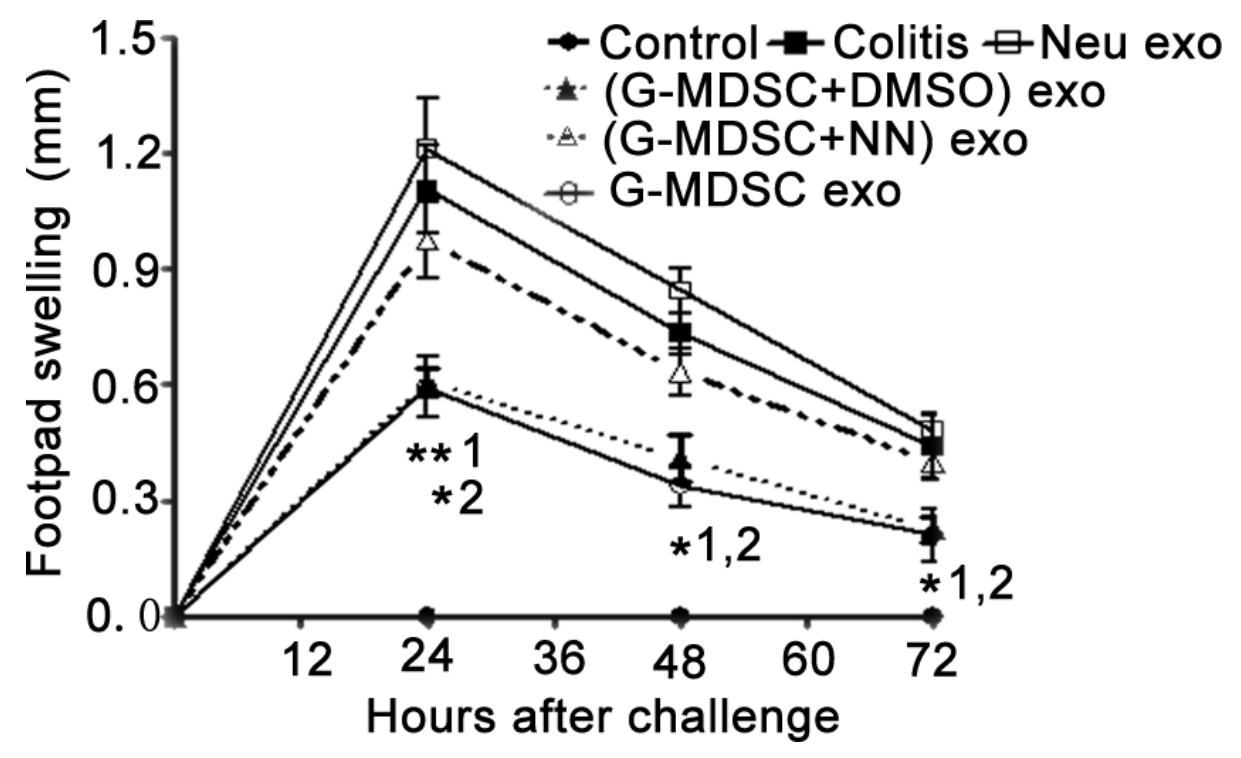

Figure 5: G-MDSC exo suppress the DTH reaction in an Arg-1-dependent manner. OVA-sensitized mice were challenged with OVA in the footpads, and paw edema was measured at 24, 48, and $72 \mathrm{~h}$ after the challenge. Footpad swelling was calculated according to the formula described in the methods. Data are shown as the mean \pm SEM of each group $(n=6)$ pooled from three independent experiments. ${ }^{*} p<0.05,{ }^{*} p<0.01 ; 1$, G-MDSC exo-treated DTH mice versus DTH mice; 2 , G-MDSC exo-treated DTH mice versus $(\mathrm{G}-\mathrm{MDSC}+\mathrm{NN})$ exo-treated DTH mice, analyzed by ANOVA and $Q$ test. 
receptor (TCR). This reaction damages the conformational flexibility of TCR complex, and inhibits its binding with peptide-loaded MHC and leads to the unresponsiveness of $\mathrm{T}$ cells to antigen-specific stimulation [8, 15, 36, 37]. The suppressive activity of Arg-1 is based on its role in the hepatic urea cycle, metabolizing L-arginine to L-ornithine. Expression of Arg-1 has been reported to decrease CD3 $\xi$ chain biosynthesis and down-regulate TCR on cell surface and leads to the unresponsiveness of T cells without $\mathrm{MHC}$ II restriction and in an antigen-non-specific manner [38]. In our study, G-MDSC exo mediate their suppressive activity on autoimmune IBD mice through preventing Th1 cell reaction which depended on Arg-1 activity. These regulation on $\mathrm{T}$ effector immune responses without MHC II restriction and in an antigen-non-specific manner. Collectively, these results showed that G-MDSC exo can inhibit DSS-induced colitis, and this was associated with Arg-1 activity-mediated suppression of Th1 cells and Tregs expansion.
To demonstrate the immunosuppressive effect of G-MDSC exo, we observed the roles of G-MDSC exo on $\mathrm{CD}^{+} \mathrm{T}$ cell proliferation and Tregs expansion in vitro. We found that G-MDSC exo could inhibit $\mathrm{CD}^{+}$ $\mathrm{T}$ cell proliferation and IFN- $\gamma$ secretion, and these effects correlated with Arg-1 activity. Moreover, these effects were further confirmed by our observation that G-MDSC exo alleviated the DTH reaction in vivo. In addition, we found G-MDSC exo promoted Tregs expansion from $\mathrm{CD}^{+} \mathrm{T}$ cells in the presence of TGF- $\beta$, although the exact reasons need further study. One certainty is that MDSC promote Tregs expansion $[26,27,39]$. This is consistent with the theory that exosomes have some properties in common with their parent cells. These experimental results suggested G-MDSC exo have strong immunosuppressive activity in vitro and are consistent with the roles of G-MDSC exo in DSS-induced colitis.

In conclusion, we successfully isolated and identified G-MDSC exo, providing an experimental basis for further

A

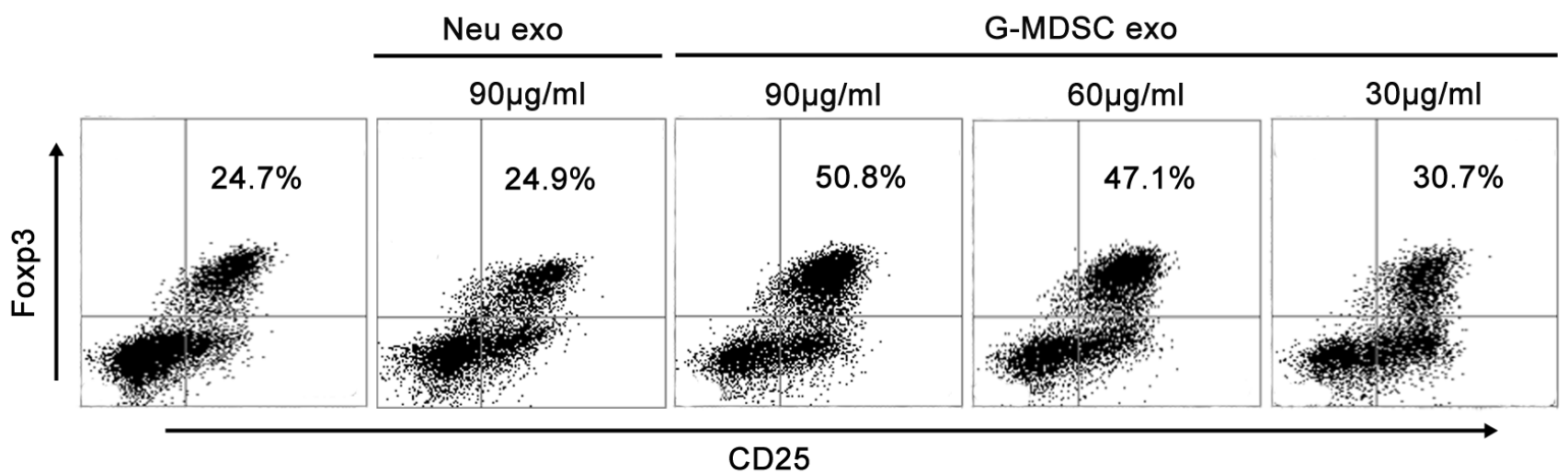

B

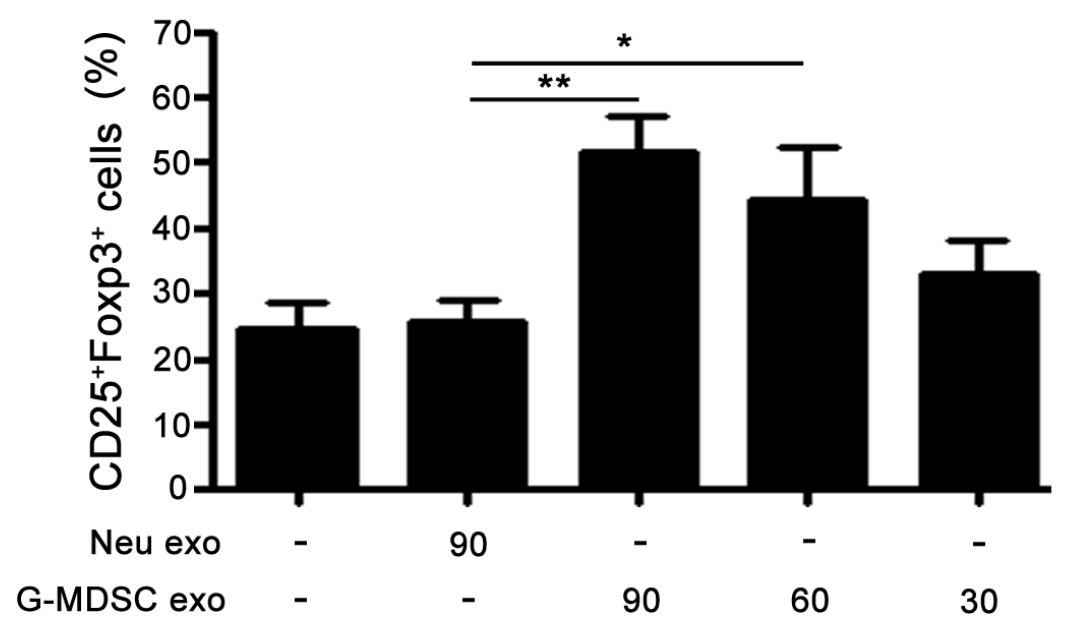

Figure 6: G-MDSC exo promote TGF- $\beta$ induced Tregs generation from $\mathbf{C D}^{+} \mathbf{T}$ cells. $1.5 \times 10^{6} / \mathrm{ml} \mathrm{CD}^{+} \mathrm{T}$ cells were isolated from the spleen of C57BL/6 mice and cultured for $72 \mathrm{~h}$ with anti-CD3 $(2 \mu \mathrm{g} / \mathrm{ml})$, anti-CD28 $(2 \mu \mathrm{g} / \mathrm{ml}) \mathrm{Ab}$, and TGF- $\beta$ (5 ng/ml) in the presence or absence of exo isolated from G-MDSC or neutrophils. The cells were stained with anti-mouse CD4, CD25, and Foxp3 mAbs. The cells were gated first on living lymphocytes and then $\mathrm{CD}^{+} \mathrm{T}$ cells. Tregs percentages were analyzed by FCM. Representative dot plots of Tregs (A) and the percentages of Tregs from different treatments $(\mathbf{B})$. Data are shown as the mean \pm SEM of each group $(n=6)$ pooled from three independent experiments, analyzed by ANOVA and $Q$ test.. $* P<0.05$; $* * P<0.01$. 
studies. Our findings suggest that G-MDSC exo attenuate DSS-induced murine colitis by suppressing pathogenic Th1 cells and inducing Tregs differentiation and the protective effect correlated with arginase activity in MDSC exo. Moreover, these immunosuppressive effects of G-MDSC exo were confirmed in vitro. In conclusion, our work provides a new way in the development of an effective intervention of IBD and other autoimmune diseases.

\section{MATERIALS AND METHODS}

\section{Antibodies and reagents}

$\mathrm{CD}^{+} \mathrm{T}$ cells, G-MDSC isolation kits, and phycoerythrin (PE)-conjugated anti-mouse interferon (IFN)-g were from Miltenyi Biotec (Bergisch Gladbach, Germany). PE, fluorescein isothiocyanate (FITC), PE-Cy5conjugated anti-mouse CD4 mAb (L3T4), PE-conjugated anti-mouse Foxp3 mAb (FJK-16s), and Cy5.5-conjugated anti-mouse CD25 mAb (PC61.5) were from eBioscience (San Diego, CA, USA). PE-conjugated anti-mouse Ly-6G mAb (RB6-8C5), CD11b mAb (M1/70), anti-CD3 mAb, and anti-CD28 mAb were from Biolegend (San Diego, CA, USA). Mouse mAbs against CD63 (Y-18) and calnexin (C8. B6) were from Abcam (Cambridge, UK). IFN-g and tumor necrosis factor (TNF)- $\alpha$ enzyme-linked immunosorbent assay (ELISA) kits were from MultiSciences (Shanghai, China). QuantiChrom ${ }^{\mathrm{TM}}$ arginase assay kits were from Bioassays (Hayward, CA, USA). ExoQuick-TCTM Exosomes were from SBI (Mountain View, CA, USA). Recombinant mouse TGF- $\beta$ was from PeproTech (Rocky Hill, NJ, USA). MicroBCA protein assay kits were from Beijing ComWin Biotech (Beijing, China). Ovalbumin (OVA) and complete Freund's adjuvant (CFA) were from Sigma (St. Louis, MO, USA). $\mathrm{N}^{\omega}$-hydroxy-nor-Arginine was from Cayman (Ann Arbor, MI, USA).

\section{Mice}

Male C57BL/6 mice (6-8 weeks old, weighing 18-22 g) were from the Animal Research Center of Jiangsu University (Zhenjiang, China) and were housed in a specific pathogen-free facility. The experimental protocols were approved by the Jiangsu University Animal Ethics and Experimentation Committee.

\section{G-MDSC isolation}

Tumor-bearing mice were established with the Lewis lung adenocarcinoma cell line according to a method previously used in our laboratory $[9,40]$. When tumors were greater than $2 \mathrm{~cm}$ in diameter, G-MDSC were harvested from the spleen with G-MDSC isolation kits according to the manufacturer's instructions, and their purity was assessed by measuring the expression of Ly-6G and CD11b with flow cytometry (FCM).

\section{G-MDSC exo purification}

To make preparations for large-scale exosomes purification, isolated G-MDSC were cultivated in an incubator at $37^{\circ} \mathrm{C}$ and $5 \% \mathrm{CO}_{2}$ for $20 \mathrm{~h}$ in G-MDSCconditioned medium (R1640 with 10\% fetal bovine serum that had been ultracentrifuged at $100,000 \mathrm{~g}$ for $16 \mathrm{~h}$ at $4^{\circ} \mathrm{C}$ ). The culture supernatant of G-MDSC was harvested after $20 \mathrm{~h}$. Exosomes were purified from the supernatant by differential centrifugation and ultrafiltration membrane technology followed by the use of an exosomes extraction kit. In brief, cells and cellular debris were removed by sequential centrifugation at $500 \mathrm{~g}$ for $10 \mathrm{~min}, 1000 \mathrm{~g}$ for $30 \mathrm{~min}$, and $10000 \mathrm{~g}$ for $30 \mathrm{~min}$. The concentrated supernatant was acquired by an ultrafiltration membrane with a molecular weight cut-off ranging from 2 to $100 \mathrm{kDa}$. The supernatant was passed through a $0.22-\mu \mathrm{m}$ microcentrifuge filter. The filtrate was mixed with exosomes isolation reagent $(\mathrm{v} / \mathrm{v}=5: 1)$ and incubated for $16 \mathrm{~h}$ at $4{ }^{\circ} \mathrm{C}$. Finally, the mixture was centrifuged at $1000 \mathrm{~g}$ for $30 \mathrm{~min}$, and the precipitate was G-MDSC exo. Exosomes were dissolved in phosphate-buffered saline (PBS) and stored at $-80^{\circ} \mathrm{C}$. The protein contents of G-MDSC exo were quantified using a microBCA protein assay kit. In this study, we also prepared neutrophilderived exo (Neu exo), which served as control for G-MDSC exo.

In the purification process of $(\mathrm{G}-\mathrm{MDSC}+\mathrm{NN})$ exo in which the Arg-1 activity is inhibited, G-MDSC used to extract exosomes were cultured in the presence of $200 \mu \mathrm{M}$ nor-NOHA, which is a potent inhibitor of arginase. Because nor-NOHA is dissolved in dimethyl sulfoxide (DMSO), we prepared (G-MDSC+DMSO) exo as solvent to control for the influence of DMSO on the experiment.

\section{G-MDSC exo transmission microscopic examination}

Purified G-MDSC exo suspended in 2\% glutaraldehyde in PBS were loaded on a formvar-coated grid and negatively stained with 3\% (w/v) aqueous phosphotungstic acid for $1 \mathrm{~min}$. Electron micrographs were observed by transmission electron microscopy (Tecnai-12; Philips, Amsterdam, Netherlands).

\section{Western blot analysis}

G-MDSC and G-MDSC exo were lysed in radioimmunoprecipitation (RIPA) buffer, and lysates were separated by $12 \%$ sodium dodecyl sulfate-polyacrylamide gel electrophoresis (SDS-PAGE) and subsequently electrotransferred onto Immobilon polyvinylidene membranes (Bio-Rad, Hercules, CA, USA), and probed with mouse mAbs against CD63 or calnexin, and HRP conjugated anti-mouse IgG followed by chemiluminescent detection (Champion Chemical, Whittier, CA, USA). 


\section{Detection of arginase activity}

Arg-1 activity contents in the lysates from exosomes or G-MDSC were measured by Arg-1 activity assay according to the manufacturer's protocols. Briefly, $2 \times 10^{6}$ G-MDSC or exosomes isolated from $2 \times 10^{6} \mathrm{G}-\mathrm{MDSC}$ or neutrophil were lysed in $50 \mu \mathrm{l}$ RIPA buffer, collected the lysate by centrifugation at $14000 \mathrm{~g}$ for $10 \mathrm{~min}$ at $4^{\circ} \mathrm{C}$, and added $\mathrm{ddH}_{2} \mathrm{O}$ to $100 \mu \mathrm{l}$. Arginase activity was detected with the QuantiChrom Argianse Assay kit (BioAssay systems, Hayward, CA) following the manufacturer's instructions.

\section{DSS-induced experimental colitis in mice}

DSS-induced murine experimental colitis was established as described previously with minor modification [41]. Briefly, male C57BL/6 mice were treated with $2.5 \%$ DSS in drinking water for 10 days to induce colon injury and colitis, and these mice were treated with PBS or exosomes (30 $\mu \mathrm{g} / \mathrm{mouse} / \mathrm{i} . \mathrm{p})$ on days 2, 4, and 6 after DSS drinking. Normal control mice were given normal drinking water and were treated with PBS. Weight loss, rectal bleeding and diarrhea were monitored daily for 10 days and graded separately on scales of $0-4$. The average of the three values constitutes the disease activity index (DAI). Mice were sacrificed on day 8 by eye bloodletting followed by cervical dislocation. Colons were mechanically isolated, cleaned, and measured in length. After removing caecum and adipose tissue, the colons were fixed in 10\% formalin solution, paraffin-embedded, sections, stained with hematoxylin and eosin ( $\mathrm{H} \& \mathrm{E}$ ), and examined under a light microscope. Histological scoring was done as described previously [42].

\section{FCM analysis}

On day 8 , mice were sacrificed by eye bloodletting followed by cervical dislocation. MLNs were isolated and grinded in $2 \mathrm{ml}$ PBS. The cell suspensions were filtered through $70 \mu \mathrm{m}$ cell strainers. The lymphocytes were collected by centrifugation at $500 \mathrm{~g}$ for $5 \mathrm{~min}$ at $4{ }^{\circ} \mathrm{C}$. For Tregs detection, lymphocytes were stained with antimouse CD4 and CD25 and Foxp3 mAbs, and defined the proportion of $\mathrm{CD}_{2} 5^{+} \mathrm{Foxp}^{+}$lymphocytes gated in $\mathrm{CD}^{+}$ lymphocytes as described previously [43]. For the detection of Th1 cells, single-cell suspensions were stimulated with $50 \mathrm{ng} / \mathrm{ml}$ phorbol myristate acetate, $1 \mu \mathrm{g} / \mathrm{ml}$ ionomycin, and $2 \mu \mathrm{g} / \mathrm{ml}$ monensin. After $5 \mathrm{~h}$, cells were stained with anti-CD3 and anti-CD4 mAbs, fixed, permeabilized, and stained with anti-IFN- $\gamma$ mAb according to the intracellular staining kit (Invitrogen, Carlsbad, CA, USA) instructions. Defined the proportion of $\mathrm{CD}^{+} \mathrm{IFN}-\gamma^{+}$ lymphocytes gated in $\mathrm{CD}^{+}$lymphocytes.

\section{ELISA}

On day 8 , mice were sacrificed by eye bloodletting followed by cervical dislocation. The eyeball blood was collected into $1.5 \mathrm{ml}$ EP tubes without anticoagulant and the serum was isolated by centrifugation for $5 \mathrm{~min}$ at $3000 \mathrm{rpm}$. IFN- $\gamma$ and TNF- $\alpha$ contents in the serum from different groups of mice were detected with the Mouse IFN- $\gamma$ or TNF- $\alpha$ SunnyELISA Assay kit (Multi sciences, Hangzhou, China) following the manufacturer's instructions.

\section{T-cell proliferation assay}

For in vitro experiments, $\mathrm{CD} 4^{+} \mathrm{T}$ cells were isolated from the splenocytes of wild-type C57BL/6 mice with a CD4 ${ }^{+} \mathrm{T}$ cell isolation kit as previously described [44]. Briefly, $1 \times 10^{6} / \mathrm{ml}$ cells were stimulated with anti-CD3 $(5 \mu \mathrm{g} / \mathrm{ml})$ and anti-CD28 $(1 \mu \mathrm{g} / \mathrm{ml}) \mathrm{mAbs}$ in triplicate in round-bottom 96 wells. Different doses of each type of exosomes were added into the wells. Cells were cultured in a humidified $5 \% \mathrm{CO}_{2}$ atmosphere at $37^{\circ} \mathrm{C}$ for $72 \mathrm{~h}$, and $\left[{ }^{3} \mathrm{H}\right]$-thymidine $(1 \mu \mathrm{Ci} /$ well; Pharmacia, Uppsala, Sweden $)$ was added for the last $16 \mathrm{~h}$. The counts per minute (CPM) values of various wells were detected with an LS6500 multi-purpose scintillation counter (Beckman Coulter, Brea, CA, USA).

\section{Induction of $\mathrm{CD}^{+} \mathrm{CD}^{+} 5^{+} \mathrm{Foxp3}^{+}$Tregs}

$\mathrm{CD}^{+} \mathrm{T}$ cells isolated from $\mathrm{C} 57 \mathrm{BL} / 6$ mice splenocytes were cultured with anti-CD3 and anti-CD28 mAbs in the presence or absence of $5 \mathrm{ng} / \mathrm{ml}$ TGF- $\beta$ in a 24-well plate for $72 \mathrm{~h}$ in complete RPMI medium $\left(1.5 \times 10^{6}\right.$ cells $/$ well $)$ with or without exo isolated from G-MDSC or neutrophils. The percentages of $\mathrm{CD} 25^{+} \mathrm{Foxp} 3^{+}$cells in $\mathrm{CD} 4^{+} \mathrm{T}$ cells were determined by FCM after $72 \mathrm{~h}$.

\section{Induction of DTH}

DTH was induced in mice by challenging the footpad of previously sensitized mice with OVA as described previously [45]. In brief, C57BL/6 mice were sensitized by intradermal injections of $1 \mathrm{mg} / \mathrm{ml} \mathrm{CFA-emulsified}$ OVA peptide (grade V) in a final volume of $200 \mu \mathrm{l}$ at the tail base and back. Seven days after sensitization, each mouse was challenged by footpad injection of 20 $\mathrm{mg} / \mathrm{ml}$ PBS-dissolved OVA peptide (grade II) in a final volume of $30 \mu \mathrm{l}$. Another rear paw was injected with a comparable volume of PBS as a control. Footpad thickness was measured using a vernier caliper (Mitutoyo Corp, Tokyo, Japan) at a given time after the challenge. The magnitude of the DTH response was determined as follows: DTH units=(footpad thickness of OVA injection 
[mm])-(footpad thickness of PBS injection [mm]). For DTH treatment, mice were intraperitoneally (i.p.) injected with different exosomes (30 $\mu \mathrm{g} / \mathrm{mouse} /$ injection) on days 2,4 , and 6 after sensitization.

\section{Statistical analysis}

The statistical significance of differences between groups was analyzed by ANOVA and $Q$ test using the SPSS version 16.0 for Windows (SPSS Inc, Chicago, IL, USA). The data are presented as the mean \pm SEM from at least three independent experiments. A $p$-value $<0.05$ was considered statistically as significant.

\section{ACKNOWLEDGMENTS}

We gratefully thank Dr. Miao Chen for providing technical assistance with the pathological examination.

\section{FUNDING}

This work was supported by the Jiangsu Province "333" Project (Grant No. BRA2015197), National Natural Science Foundation of China (Grant Nos. 31470881, 31170849), Specialized Project for Clinical Medicine of Jiangsu Province (Grant No. BL2014065), Natural Science Foundation of Jiangsu (Grant No. BK20150533), Specialized Research Fund for the Doctoral Program of Higher Education (Grant No. 20133227110008), Health Department Foundation of Jiangsu Province (Grant No. Z201312), Science and Technology Support Program (Social Development) of Zhenjiang (Grant No. SH2014039), Summit of the Six Top Talents Program of Jiangsu Province (Grant No. 2015-WSN-116), Jiangsu University Science Foundation (Grant Nos. 15JDG070, 11JDG093, FCJJ2015022), and Priority Academic Program Development of Jiangsu Higher Education Institutions.

\section{Authors' contributions}

YW and SW conceived the study. YW, JT, XT, KR, $\mathrm{XTi}$, JM, and BM performed experiments. YW, JT, and SW analysed the data. YW and SW wrote the manuscript. HX and LL critically revised the manuscript.

\section{CONFLICTS OF INTEREST}

The authors declared no potential conflicts of interest.

\section{REFERENCES}

1. Coskun M. Intestinal epithelium in inflammatory bowel disease. Front Med (Lausanne). 2014; 1:24.
2. Missaghi B, Barkema HW, Madsen KL, Ghosh S. Perturbation of the human microbiome as a contributor to inflammatory bowel disease. Pathogens. 2014; 3:510-527.

3. Park JW, Bae H, Lee G, Hong BG, Yoo HH, Lim SJ, Lee K, Kim J, Ryu B, Lee BJ, Bae J, Lee H, Bu Y. Prophylactic effects of Lonicera japonica extract on dextran sulphate sodium-induced colitis in a mouse model by the inhibition of the Th1/Th17 response. Br J Nutr. 2013; 109:283-292.

4. Hofseth LJ, Singh UP, Singh NP, Nagarkatti M, Nagarkatti PS Taming the beast within: resveratrol suppresses colitis and prevents colon cancer. Aging (Albany NY). 2010; 2:183-184.

5. Canavan JB, Scotta C, Vossenkamper A, Goldberg R, Elder MJ, Shoval L, Marks E, Stolarczyk E, Lo JW, Powell N, Fazekasova H, Irving PM, Sanderson JD, et al. Developing in vitro expanded CD45RA ${ }^{+}$regulatory T cells as an adoptive cell therapy for Crohn's disease. Gut. 2015. doi: 10.1136/gutjnl-2014-306919.

6. Abarbanel DN, Seki SM, Davies Y, Marlen N, Benavides JA, Cox K, Nadeau KC, Cox KL. Immunomodulatory effect of vancomycin on Treg in pediatric inflammatory bowel disease and primary sclerosing cholangitis. J Clin Immunol. 2013; 33:397-406.

7. Amiot A, Peyrin-Biroulet L. Current, new and future biological agents on the horizon for the treatment of inflammatory bowel diseases. Therap Adv Gastroenterol. 2015; 8:66-82.

8. Gabrilovich DI, Nagaraj S. Myeloid-derived suppressor cells as regulators of the immune system. Nat Rev Immunol. 2009; 9:162-174.

9. Tian J, Rui K, Tang X, Ma J, Wang Y, Tian X, Zhang Y, $\mathrm{Xu} \mathrm{H}$, Lu L, Wang S. MicroRNA-9 Regulates the Differentiation and Function of Myeloid-Derived Suppressor Cells via Targeting Runx1. J Immunol. 2015; 195:1301-1311.

10. Movahedi K, Guilliams M, Van den Bossche J, Van den Bergh R, Gysemans C, Beschin A, Beschin A, De Baetselier P, Van Ginderachter JA. Identification of discrete tumor-induced myeloid-derived suppressor cell subpopulations with distinct T cell-suppressive activity. Blood. 2008; 111:4233-4244.

11. Zea AH, Rodriguez PC, Atkins MB, Hernandez C, Signoretti S, Zabaleta J, McDermott D, Quiceno D, Youmans A, O’Neill A, Mier J, Ochoa AC. Arginase-producing myeloid suppressor cells in renal cell carcinoma patients: a mechanism of tumor evasion. Cancer Res. 2005; 65:3044-3048.

12. Tian X, Tian J, Tang X, Rui K, Zhang Y, Ma J, Wang Y, $\mathrm{Xu} \mathrm{H}, \mathrm{Lu} \mathrm{L}$, Wang S. Particulate $\beta$-glucan regulates the immunosuppression of granulocytic myeloidderived suppressor cells by inhibiting NFIA expression. Oncoimmunology. 2015; 4:e1038687.

13. Yang H, Bi Y, Han F, Lu Y, Wang J, Zhang Z, Liu G. Myeloid-derived suppressor cells in immunity and autoimmunity. ExpertRev Clin Immunol. 2015; 11:911-919.

14. Crook KR, Liu P. Role of myeloid-derived suppressor cells in autoimmune disease. World J Immunol. 2014; 4:26-33. 
15. Ioannou M, Alissafi T, Lazaridis I, Deraos G, Matsoukas J, Gravanis A, Mastorodemos V, Plaitakis A, Sharpe A, Boumpas D, Verginis P. Crucial role of granulocytic myeloid-derived suppressor cells in the regulation of central nervous system autoimmune disease. J Immunol. 2012; 188:1136-1146.

16. Katerina Vlachou, Konstantinos Mintzas, Maria Glymenaki, Marianna Ioannou, Garyfalia Papadaki, George K Bertsias, Prodromos Sidiropoulos, Dimitrios T. Boumpas, Panayotis Verginis. Elimination of granulocytic myeloid-derived suppressor cells in lupus-prone mice due to ROS-dependent extracellular trap formation. Arthritis Rheumatol. 2016; 68:449-461.

17. Ostanin DV, Bhattacharya D. Myeloid-derived suppressor cells in the inflammatory bowel diseases. Inflamm Bowel Dis. 2013; 19:2468-2477.

18. Kim YJ, Chang SY, Ko HJ. Myeloid-derived suppressor cells in inflammatory bowel disease. Intest Res. 2015; 13:105-111.

19. Record M, Subra C, Silvente-Poirot S, Poirot M. Exosomes as intercellular signalosomes and pharmacological effectors. Biochem Pharmacol. 2011; 81:1171-1182.

20. Beninson LA, Fleshner M. Exosomes: an emerging factor in stress-induced immunomodulation. Semin Immunol. 2014; 26:394-401.

21. van der Pol E, Böing AN, Harrison P, Sturk A, Nieuwland R. Classification, functions, and clinical relevance of extracellular vesicles. Pharmacol Rev. 2012; 64:676-705.

22. Burke M, Choksawangkarn W, Edwards N, OstrandRosenberg S, Fenselau C. Exosomes from myeloidderived suppressor cells carry biologically active proteins. J Proteome Res. 2014; 13:836-843.

23. Marcus ME, Leonard JN. FedExosomes: Engineering therapeutic biological nanoparticles that truly deliver. Pharmaceuticals (Basel). 2013; 6:659-680.

24. Yin W, Ouyang S, Li Y, Xiao B, Yang H. Immature dendritic cell-derived exosomes: a promise subcellular vaccine for autoimmunity. Inflammation. 2013; 36:232-240.

25. Singh UP, Murphy AE, Enos RT, Shamran HA, Singh NP, Guan H, Hegde VL, Fan D, Price RL, Taub DD, Mishra MK, Nagarkatti M, Nagarkatti PS. miR-155 deficiency protects mice from experimental colitis by reducing $\mathrm{T}$ helper type 1/type 17 responses. Immunology. $2014 ; 143: 478-489$.

26. Serafini P, Mgebroff S, Noonan K, Borrello I. Myeloidderived suppressor cells promote cross-tolerance in B-cell lymphoma by expanding regulatory $\mathrm{T}$ cells. Cancer Res. 2008; 68:5439-5449.

27. Huang B, Pan PY, Li Q, Sato AI, Levy DE, Bromberg J, Divino CM, Chen SH. Gr- $1^{+} \mathrm{CD} 115^{+}$immature myeloid suppressor cells mediate the development of tumor-induced $\mathrm{T}$ regulatory cells and T-cell anergy in tumor-bearing host. Cancer Res. 2006; 66:1123-1131.
28. Gould SJ, Raposo G. As we wait: coping with an imperfect nomenclature for extracellular vesicles. J Extracell Vesicles. 2013; 2. doi: 10.3402/jev.v2i0.20389.

29. Moliné-Velázquez V, Cuervo H, Vila-Del Sol V, Ortega MC, Clemente D, de Castro F. Myeloidderived suppressor cells limit the inflammation by promoting $\mathrm{T}$ lymphocyte apoptosis in the spinal cord of a murine model of multiple sclerosis. Brain Pathol. 2011; 21:678-691.

30. Fujii W, Ashihara E, Hirai H, Nagahara H, Kajitani N, Fujioka K, Murakami K, Seno T, Yamamoto A, Ishino H, Kohno M, Maekawa T, Kawahito Y. Myeloid-derived suppressor cells play crucial roles in the regulation of mouse collagen-induced arthritis. J Immunol. 2013; 191:1073-1081.

31. Haile LA, von Wasielewski R, Gamrekelashvili J, Krüger C, Bachmann O, estendorf AM, Buer J, Liblau R, Manns MP, Korangy F, Greten TF. Myeloid-derived suppressor cells in inflammatory bowel disease: new immunoregulatory pathway. Gastroenterology. 2008; 135:871-881.

32. Ostanin DV, Kurmaeva E, Furr K, Bao R, Hoffman J, Berney S, Grisham MB. Acquisition of antigen-presenting functions by neutrophils isolated from mice with chronic colitis. J Immunol. 2012; 188:1491-1502.

33. Rivollier A, He J, Kole A, Valatas V, Kelsall BL. Inflammation switches the differentiation program of Ly $6 \mathrm{C}^{\text {hi }}$ monocytes from antiinflammatory macrophages to inflammatory dendritic cells in the colon. J Exp Med. 2012; 209:139-155.

34. Kurmaeva E, Bhattacharya D, Goodman W, Omenetti S, Merendino A, Berney S, Pizarro T, Ostanin DV. Immunosuppressive monocytes: possible homeostatic mechanism to restrain chronic intestinal inflammation. J Leukoc Biol. 2014; 96:377-389.

35. Kusmartsev S, Nefedova Y, Yoder D, Gabrilovich DI. Antigen-specific inhibition of CD8 $+\mathrm{T}$ cell response by immature myeloid cells in cancer is mediated by reactive oxygen species. J Immunol. 2004; 172:989-999.

36. Nagaraj S, Gupta K, Pisarev V, Kinarsky L, Sherman S, Kang L, Herber DL, Schneck J, Gabrilovich DI. Altered recognition of antigen is a mechanism of $\mathrm{CD} 8^{+} \mathrm{T}$ cell tolerance in cancer. Nat Med. 2007; 13:828-835.

37. Gabrilovich DI, Ostrand-Rosenberg S, Bronte V. Coordinated regulation of myeloid cells by tumours. Nat Rev Immunol. 2012; 12:253-268.

38. Rodriguez PC, Zea AH, Culotta KS, Zabaleta J, Ochoa JB, Ochoa AC. Regulation of T cell receptor CD3zeta chain expression by L-arginine. J Biol Chem. 2002; 277:2112321129.

39. Yang R, Cai Z, Zhang Y, Yutzy WH 4th, Roby KF, Roden RB. CD80 in immune suppression by mouse ovarian carcinomaassociated Gr- $1^{+} \mathrm{CD} 11 b^{+}$myeloid cells. Cancer Res. 2006; 66:6807-6815.

40. Tian J, Ma J, Ma K, Guo H, Baidoo SE, Zhang Y, Yan J, Lu L, $\mathrm{Xu} \mathrm{H}$, Wang $\mathrm{S}$. $\beta$-Glucan enhances antitumor immune 
responses by regulating differentiation and function of monocytic myeloid-derived suppressor cells. Eur J Immunol. 2013; 43:1220-1230.

41. Bian Z, Li L, Cui J, Zhang H, Liu Y, Zhang CY, Zen K. Role of miR-150-targeting c-Myb in colonic epithelial disruption during dextran sulphate sodium-induced murine experimental colitis and human ulcerative colitis. J Pathol. 2011; 225:544-553.

42. Obermeier F, KojouharoffG, Hans W, Schölmerich J, Gross V, Falk W. Interferon-gamma (IFN-gamma)- and tumour necrosis factor (TNF)-induced nitric oxide as toxic effector molecule in chronic dextran sulphate sodium (DSS)-induced colitis in mice. Clin Exp Immunol. 1999; 116:238-2345.
43. Tian J, Ma J, Ma K, Ma B, Tang X, Baidoo SE, Tong J, Yan J, Lu L, Xu H, Wang S. Up-regulation of GITRL on dendritic cells by WGP improves anti-tumor immunity in murine Lewis lung carcinoma. PloS One. 2012; 7:e46936.

44. Chen Y, Tian J, Tian X, Tang X, Rui K, Tong J, Lu L, $\mathrm{Xu} \mathrm{H}$, Wang S. Adipose tissue dendritic cells enhances inflammation by prompting the generation of Th17 cells. PloS One. 2014; 9:e92450.

45. Reis EF, Castro SB, Alves CC, Oliveira EE, Corrêa TA, Almeida MV, Ferreira AP. Lipophilic amino alcohols reduces carrageenan-induced paw edema and anti-OVA $\mathrm{DTH}$ in BALB/c mice. Int Immunopharmacol. 2013; 17:727-732. 